\title{
The Application of Sandbox Game Therapy in Higher Vocational College Students' Mental Health Education
}

\author{
Qi Xiang Sun $^{1}$, Xiao Jiang Chen ${ }^{2 *}$ \\ Jiangsu Agri-animal Husbandry Vocational College, Taizhou City, Jiangsu Province, China
}

\begin{abstract}
To make more readers get familiar with the sand table game therapy, this paper has given an introduction to aspects of the features, roles and the implementation steps of the sand table game therapy as well as the individual sand table therapy and group sand table therapy, indicating that the sand table game therapy would help to higher vocational students improve their self - catharsis of negative emotions, the release of stress and improving the interpersonal skills and self - confidence, and play a therapeutic role in students' psychological problems.
\end{abstract}

Keywords: mental health; sandbox game therapy; health education, sand play, Higher Vocational College

\section{Introduction}

20 years ago, sand table game theory has been put forward by researcher ${ }^{[1-2]}$. In the recent decade, the sandbox game technology has been introduced to schools by American teachers and school counselors to assist the launching of psychological counseling ${ }^{[3-6]}$. As the diagnostic, therapeutic and educational significance contained, it has drew the attention of many educators ${ }^{[7]}$, and the integration of sandbox game therapy into the school mental health education has also become an important research trend ${ }^{[8]}$.

\section{Features of the sandbox game therapy}

\subsection{To provide free and protected space}

The sandbox game therapy provides a free and protected space, where students could do whatever they want to do at will, with the unconsciousness naturally show. At this moment, their feelings and comprehension are free and safe, and meanwhile they can also feel their own development and changes.

\subsection{Fun from the game}

As a game, the sandbox game therapy is the activity driven by the human nature which could make people feel happy and relaxed, freely express their own heart and obtain the psychological satisfaction. In the sandbox game therapy, the therapist should maintain the interests of the visitor as much as possible from the point of view of the visitor, and visitors will display themselves in the warm, free and inclusive environment without impedance to satisfy the psychological satisfaction to be gradually integrated and achieve psychological growth $^{[9]}$.

\subsection{Release of the mental energy}

The sandbox game therapy is a process to release the mental energy. In the process of sand table game treatment, consciousness and unconsciousness would actively communicate and talk, and the work could be the scene of the confrontation from conflicts ugliness, or other scenes unfamiliar to the therapist. Through these images, the producer's mental energy gets released, the psychological pressure gets relieved, the psychological problems are solved, and visitors' self-healing ability is stimulated to achieve their self-integration ${ }^{[10]}$.

2. The research of the sandbox game therapy in higher vocational college students' mental health education

\subsection{The role of the sandbox therapy in higher vocational college students' mental health education}

Psychological problems of vocational students are mainly reflected as low self-esteem, emotional impulses, instability, lack in interpersonal skills and eagerness to have friends but with the difficulty in opening the mind. To solve these psychological problems of students, based on the combination of higher vocational students' learning characteristics of likes in operation and hatred in theory, the sandbox game therapy should be applied in the mental health education work of vocational colleges.

Unlimited to languages, the sandbox game therapy has its unique function of awakening people's unconscious and physical feeling. Visiting students will naturally have a lot of images in mind in face of sand tables and sand tools, the models of all kinds of characters, animals, plants, transport and daily necessities, as well as sensory experience on the sand and water would stimulate the occurrence of unconsciousness, and could 
reflect the communication between students' mind and the whole natural world. The sandbox game therapy could turn the unconsciousness into consciousness, open or probe into people's mind. Visiting students' unconsciousness would get naturally revealed.

\subsection{Implementation Steps of the Sandbox Game Therapy}

With the application of the analytical psychology, we divide the entire therapy process into five steps in the practical application of sand table game therapy technology:

Step 1: create your own sand world. Firstly, introduce the sandbox game therapy method and inform the visitors that they could be helped through the sandbox game; secondly, establish a safe and protected free space to have visitors to build their own sand world in such a space.

Step 2: Experience the created world. When the visitors complete the sand table works, the therapist makes the visitors quietly feel their own work to obtain the insights in mind; after re-experiencing sand table works, visitors can move and add sand tools and particular attention to the changes in mind in the process of making the sandbox works. The therapist should encourage them to re-experience the sand world after the changes, and keep track of visitors' changes.

Step 3: the treatment in the heart-to-heart exchange. One of the sandbox game therapy is to turn visitors unconsciousness into consciousness. At this stage, the therapist to help visitors understand their own unconsciousness through the treatment techniques, try to build a bridge between the unconsciousness and the reality for the visitors, help visitors to link the unconsciousness and the reality and explore the sand world, listen carefully to visitors' complaints, give empathy, hint and questionable explanations, and meanwhile choose to use other the psychological treatment suitable for visitors to effectively promote visitors' self-exploration experience and stimulate their self-healing power.

Step 4: Return to the real world. Visitors continue to gain the experience in mind from their own works and continue to be affected by the sandbox. After this, help visitors back to reality from the dreamland, link the sandbox world and real life, as well as visitors' real world to the sandbox world. Notice how the problems in the sandbox to be displayed in his daily study, life, work and so on.

Step 5: Remove the sandbox works. It is recommended that visitors remove the sandbox works before the visitors leave, put the sand tools back to the original place where the sand rack locates, carefully recall the entire sandbox game process, especially note the place changed and take the sandbox notes. This step means that visitors have the ability to create a world and restore the original order, which is conducive to enhancing his sense of control and self-confidence.

The sandbox game therapy process with these five steps would enhance higher vocational students' physical and mental unity, complete their personality and finally realize the goal of the mental health education for higher vocational students.

3 The application of the sandbox game therapy in higher vocational college students' mental health education

\subsection{The application of individual sandbox therapy in mental health education}

By letting the individual naturally express themselves, the sandbox game could clearly find the harmony and deviation in visitors' mind and make corrections. It is of a strong therapeutic value in individuals' motional or behavioral issues, enabling them to develop intellectual, emotional and social skills, learn skills to solve problems and improve the competency ${ }^{[11]}$.

\subsubsection{Poor adaptability for new students}

Poor adaptability for new students is mainly reflected in: interpersonal tension, insomnia, black moods, as well as self-retreat and isolation, which would prevent new students integrated into the university environment as soon as possible and obtaining classmates and teachers' love in the end, resulting in a vicious circle. Thus the sandbox game therapy is applied to interfere these new students. After about 10 times of sandbox experience with four stages of displaying problem, struggling \&confrontation, transform \&growth and treatment \&integration, these new students have had certain expectations on the future from the confusion and become very open, the students can also make equal communication with their classmates in real life, get support from their own friends, and students have gained more sense of value from the experience in the sandbox.

\subsubsection{Problems in the interpersonal relationship}

Students with sensitive interpersonal relationships are not good at expressing and prone to tension with strong defense psychology in general, the traditional consultation method would make them show impedance and is difficult to achieve good results. While as a non-verbal communication, the sandbox game therapy could provide these students communication and dialogue between the unconsciousness in their deep minds, and thus 
provide the students a platform to express and understand themselves.

\subsubsection{Problem of test anxiety}

Test anxiety is one of the more prominent psychological problems for students, and the complex emotional response to the physiological cognition and behavioral interactions produced in the examination context. At present, the relaxation training is a common intervention means for the anxiety mitigation, but the continuous effect is poor. While the sandbox game therapy Sand table game therapy can effectively solve the problem of individual anxiety.

\subsection{The application of group sandbox therapy in mental health education}

Group sandbox game refers to the sandbox creation by group members in a common sandbox. The process of creating is required to follow certain criteria, and no verbal and nonverbal communication and interaction between members the group is allowed during the whole placing process. Group sandbox game could provide college students a creative and free psychological space fully supported by group members to help them to relieve the pressure. The situation and form of the game themselves could help college students to vent their inner psychological conflicts and ease the psychological stress. The projection performance of the sandbox could help college students better fully understand themselves and understand others' inner minds; and the form of group activities provide the college students more opportunities for mutual communication and mutual benefits.

\subsubsection{Problem of the in-dorm interpersonal relationship}

The in-dorm interpersonal relationship often determines students' satisfaction degree on the college life. Those students living in the dorm without the friendly, cooperative and harmonious psychological atmosphere have characteristics of depression, sensitiveness, self-defense and difficulty in cooperation, while college students living in the dorm with the harmonious relationship with roommates would have great achievement and high values in college. In the group sandbox game, members of the same dorm could openly talk about their feelings and discuss the confusion and contradictions between each other. After a thorough discussion with the sandbox game as the platform, everyone would find that the previous friction and contradictions are mostly from the wrong ideas, meanwhile the trust between each other is also built to lay a good foundation for communication for the future.

\subsubsection{Team building of student cadres}

Student cadre is a very important group in vocational colleges. They are the bridge and link contacting the teachers and students, and meanwhile they may become the leading figures the future's technical personnel team, therefore their team building becomes very important. Group sandbox game. It reduced the team's psychological pressure and impedance in the process of changing and made everyone gains a more realistic expression of their own. After implementing the group sandbox game therapy for student cadres, their sandboxes has changed from the fragmented stage to the integration \&adjustment and ultimately to a harmonious state. The refusal to each other from the beginning has turned to the acceptance from each other, members also begin to have mutual respect and mutual attention, and finally get happy. This state can also be moved to the real work for cooperation and win-win, to better serve the teachers and students.

Sandbox game could symbolically display the invisible psychology, bring enlightenment and sentiment to students, help higher vocational students to perfect themselves, vent negative emotions, release stress, improve interpersonal skills and self-confidence and play a therapeutic role in students' psychological problems. As an effective psychological counseling technology, sandbox game therapy makes the combination of the analytical psychological theory and the game therapy to give full play to the imagination of thinking and innovation and cultivate students' self-confidence, and it plays an active role in the mental health education of higher vocational students.

\section{Acknowledgment}

This work is supported by Philosophy and Social Science Research Fund Project support of Jiangsu Agri-animal Husbandry Vocational College. (Grant NO: SKZD1402).

\section{Reference}

[1]. Carey L. Sandplay therapy with a troubled child[J]. Arts in Psychotherapy, 1990, 17(3):197-209.

[2]. Carey L J. Sandplay therapy with children and families[J]. Rosenberg, 1999,(1)

[3]. Zoja E P. Sandplay Therapy: Treatment of Psychopathologies[J]. 2004.

[4]. Pattis E. Sandplay Therapy: Treatment Of Psychopathologies [Paperback][J]. 2004.

[5]. Pouliot S. System and method for using sandboxes in a managed shell: US, US 7725922 B2[P]. 2010.

[6]. Ross E, Derouin A, Halstater B, et al. Can We Learn in the Sandbox Together? Interprofessional CaseConferences as Facilitation 
Tools[J]. Medical Science Educator, 2014, 24(1):83-91

[7]. Tornqvist D. Exploratory Play in Simulation Sandbox Games: A Review of What We Know About Why Players Act Crazy[J]. International Journal of Game-Based Learning, 2014, 4(2):78-95.

[8]. Wang G J. On Application of Sandbox Therapy in School Mental Health Education [J]. Journal of Dalian Education University, 2013 .

[9]. Niu J, Zhao J. A Research on the Characteristics in Initial Sandbox of the Community Inmates[J]. China Journal of Health Psychology, 2015.

[10]. Du M, University B. On the Intervention Mechanism of Parent-Child Sand Play Therapy of English Anxiety Disorder among School Age Children[J]. Journal of Anhui Vocational College of Police Officers, 2016.

[11]. Kets d V M F R. Get Back in the Sandbox: Teaching CEOs How to Play[J]. Social Science Electronic Publishing, 2012.

[12]. Wang D. Process and Effect of Sandplay Therapy on a Who Boy Suffered Peer Victimization[J]. Chinese Journal of Clinical Ps chology, 2013 